\title{
On the go-and-stop motion of the discontinuous precipitation front
}

\author{
M. Chronowski ${ }^{1}$ · P. Zięba ${ }^{2}$
}

Received: 5 February 2020 / Revised: 26 February 2020 / Accepted: 3 March 2020 / Published online: 11 March 2020

(c) The Author(s) 2020

\begin{abstract}
The growth of lamellar structure during discontinuous precipitation occurs frequently by so-called go-and-stop fashion. The results of simulation combined with the changes of Cahn's parameter $C$ revealed two types of such motion. The process takes place in the successive stages which can be distinguished judging from the value of $\mathrm{C}$ parameter. For lower values of linear growth rate $(v=10 \div 20 \mathrm{~nm} / \mathrm{s})$ and smaller $\alpha$ lamella thickness $(100 \div 200 \mathrm{~nm})$, the full cycle with relaxation takes $4-6 \mathrm{~s}$. The faster movement of the reaction front $(v=30 \mathrm{~nm} / \mathrm{s})$ resulted in dramatic decrease of the full cycle to $\tau_{\text {total }}=0.8 \mathrm{~s}$. The same behavior is observed if the $\alpha$ lamella thickness increases beyond $200 \mathrm{~nm}$ at constant $v$ equal to $10 \mathrm{~nm} / \mathrm{s}$. Both predicted types of go-and-stop motion can experimentally be observed during growth or dissolution of discontinuous precipitates. What is the reason that particular type prevails is unknown, and this is invitation for further studies especially using high-resolution transmission electron microscope operating in in situ mode.
\end{abstract}

Keywords Discontinuous precipitation · Go-and-stop motion · Simulation of grain boundary diffusion · Cahn's parameter

\section{Introduction}

Discontinuous precipitation (DP) is the solid-state phase transformation during which the formation of the new phase occurs at the moving reaction front (RF) which is considered to be a high-angle grain boundary (GB). The transformation products represent usually the lamellar mixture of soluterich new phase $\beta$ and solute-depleted initial phase $\alpha$ having the same crystal structure as the starting supersaturated solid solution $\alpha_{\mathrm{O}}$.

In situ observation of the DP process in the high-voltage electron microscope [1] revealed that the movement of the $\alpha / \alpha_{\mathrm{o}} \mathrm{RF}$ is not continuous but rather takes place in the goand-stop fashion. The concept of the go-and-stop motion of the RF (called also jerky or oscillatory) was discussed in detail by Bögel and Gust [2]. They proposed the mechanism of periodical enrichment in the solute atoms at the RF or in its immediate vicinity. This event leads to a retardation and

P. Zięba

p.zieba@imim.pl

1 AGH-University of Science and Technology, Kraków, Poland

2 Institute of Metallurgy and Materials Science, Polish Academy of Sciences, Reymonta St. 25, 30-059 Kraków, Poland eventually to the stop of the RF migration. Then, the volume diffusion process becomes dominant, reducing the excess of solute atoms and the RF starts again to migrate.

In the case of diffusion-induced grain boundary migration (DIGM) [3] or discontinuous dissolution (DD) [4-10], the go-and-stop movement is frequently manifested by the presence of so-called "ghost images" (Fig. 1) existing in the regions swept by the migrating RF after etching with concentration-sensitive etchant. Here, the "ghost lines" parallel to the RF are likely to be associated with the stop stage, while the distance in between is relevant for the go stage.

Besides the "ghost lines," the "ghost traces" at the places where the $\beta$ phase lamellae had previously existed were also revealed after DD process by means of optical microscopy $[4,5]$, scanning $[6,7]$ and transmission electron microscopy $[8,9]$. They show strong enhancement of solute concentration as confirmed by an energy-dispersive X-ray microanalysis $[9,10]$.

One should note that in the case of DP reaction the "ghost lines" are not visible and the judgment about go-and-stop fashion of the RF motion results from the measurements of the growth distance versus time as in the in situ experiment of Abdou et al. [1]. Another possibility is to measure the solute concentration profiles across the $\alpha$ phase lamella at various distances behind the RF as in Refs. [11, 12]. 


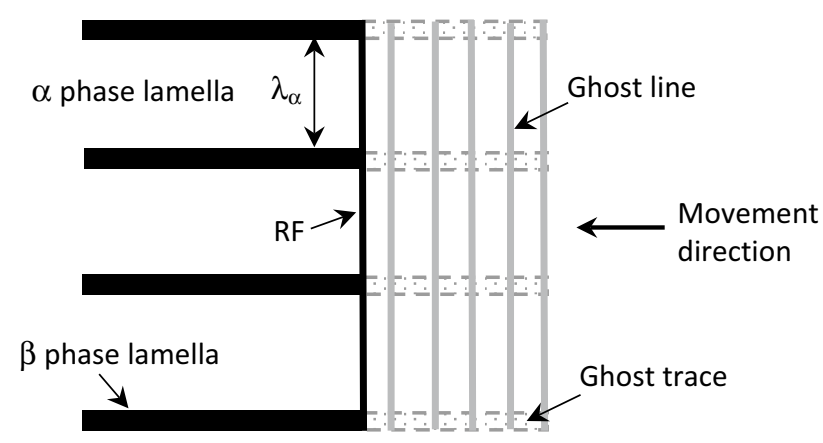

Fig. 1 Schematic representation of discontinuous dissolution with the formation of "ghost images"

In the present paper, the simple model valid for the DP process is presented which enables discrimination between go-and-stop periods based on the determination of dimensionless parameter $C$ resulting from the solution of Cahn's equation [13].

\section{Model}

The model assumes that DP is a combined reaction of RF migration and RF diffusion [11]. It means that the solute atoms enter the $\alpha / \alpha_{\mathrm{o}}$ boundary by the diffusion along the $\mathrm{RF}$ toward the solute-rich $\beta$ lamella. In order to achieve an equilibrium state within the $\alpha$ lamella, all the solute atoms have to diffuse along the boundary up to a distance of $\lambda_{\alpha} / 2$ ( $\lambda_{\alpha}-\alpha$ lamella thickness) during displacement of the RF by its own width $\delta$ at the certain velocity $v$. Usually, the time allowed for the displacement is too short and some of the solute atoms do not arrive at the edge of the solute-rich $\beta$ lamellae. They have to jump across the RF to enable the next elementary displacement. In this way, atoms which cross the $\mathrm{RF}$ contribute to form the solute concentration profile behind the RF. The number of atoms, which have to diffuse across the RF, increases with the further RF movement forming the solute profile. After a certain time, the number of atoms becomes so large that it may cause the stop of the RF to enable all the excessive atoms to enter the solute-depleted $\alpha$ lamella. Then, the RF gets relaxed and the process starts again.

In order to visualize such a process, the special procedure was prepared using HTML5, CSS3 and JavaScript technologies running on each device which supports website browsing (Fig. 2). The HTML was applied as a simple marker language in order to define positions of input data in user's browser, while CSS is a language used to describe styling: background colors, font sizes, input styles, etc. On the other hand, JavaScript was responsible for process animation, such as computing and redrawing the screen at given time interval. There are also two main canvases which are used to display the process and resulting parameters. Whole application is packed as one file, and it makes it easy to copy and run it on different devices.

The model is capable of simulating different cases using parameters which can be set by the user, such as:

$v$-linear growth rate of RF,

$\lambda_{\alpha}-\alpha$ lamella thickness,

$N_{\varepsilon}$-amount of atoms entering the RF at time $\tau$,

$N_{\text {max }}$-maximum amount of atoms entering the RF,

$S$-amount of sectors in the RF (from 0 to $\lambda_{\alpha}$ distance) used in the model,

$C_{p}$-capacity (maximum number of atoms) of each sector defined in the model.

One should emphasize that the simulation takes each sector into consideration and by using the least squares approximation is able to find function which has the best fit to the data. The simulation process can also be paused, continued and reset at any time. As the result, the solute concentration profiles left behind the moving forward RF of the discontinuous precipitates are obtained. They are described using Cahn's model [13] of DP reaction. The basic idea of this model is the balancing of the solute atom masses affected by diffusion along the RF and the motion of the RF. The solution takes the following form:

$x(y)=\left(x_{i}-x_{\mathrm{o}}\right) \frac{\cosh [(y-0.5) \sqrt{C}]}{\cosh (\sqrt{C} / 2)}+x_{o}$

in which the parameter $C$ is expressed by:

$C=\frac{v \lambda_{\alpha}^{2}}{s \delta D_{\mathrm{b}}}$

Here, $x_{\mathrm{o}}$ is the original solute content in the alloy, $x_{i}$ is the solute content in the $\alpha$ lamella in contact with the $\beta$ lamella, $v$ is the linear growth rate of RF, $\lambda_{\alpha}$ is the thickness of the $\alpha$ lamella, $s$ is the segregation factor, $\delta$ is the grain boundary (RF) width, $D_{\mathrm{b}}$ is the grain boundary diffusion coefficient, and $y$ is a co-ordinate measured from the edge of the $\beta$ lamella in the direction perpendicular to the $\alpha$ lamella.

Except of $C$ parameters, the simulation delivers, $\tau_{\mathrm{go}}-$ time during which the RF moves, $\tau_{\text {stop }}$-time necessary for all the RF excessive atoms to enter the solute-depleted $\alpha$ lamella (in other words time during which the RF is immobile) and $\tau_{\text {total }}$-time of the whole process duration.

The simulation of the growth of discontinuous precipitates was performed at the example of Al-22 at.\% alloy in which the DP process was described in detail including in situ observation $[14,15]$ and systematic studies 
Fig. 2 Flowchart of simulation procedure

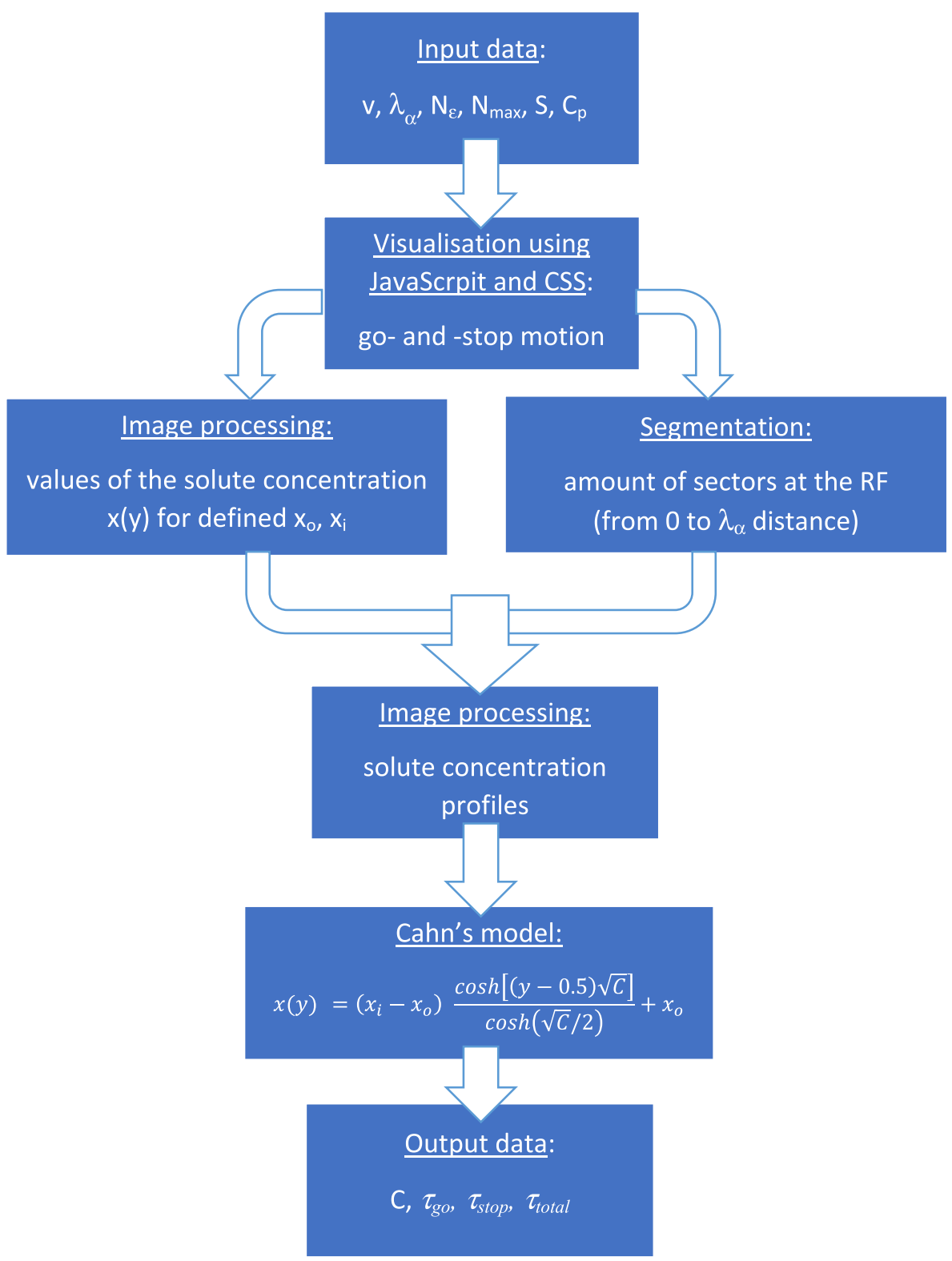

of the chemistry across the RF and $\alpha$ phase lamellae using analytical electron microscopy were performed [9, 16]. The input parameters for Eq. 1 were assumed to be $x_{\mathrm{o}}=22$ at. $\%$ and $x_{i}=4.4$ at. $\%$. Two cases were taken into consideration:

1. $v=$ const, $N_{\varepsilon}=$ const, for different values of $\lambda_{\alpha}$,

2. $\lambda_{\alpha}=$ const, $N_{\varepsilon}=$ const, for different values of $v$,

for which $v=1 \times 10^{-8} \div 4 \times 10^{-8} \mathrm{~m} / \mathrm{s}$, $\lambda_{\alpha}=1 \times 10^{-7} \div 4 \times 10^{-7} \mathrm{~m}$. Those values are typical for the linear growth rate and $\alpha$ lamella thickness in Al-22 at.\%
$\mathrm{Zn}$ alloy reported in the literature, see for example Refs. $[9,16]$.

\section{Results}

Figure 3 presents the schematic view of individual set of $\alpha$ and $\beta$ phase lamellae. The solute concentration profiles formed during go (motion) period are visualized on the right side while those relevant for the stop (relaxation) period on the left side, and denoted as $C_{1}, C_{2} \ldots C_{9}$, which corresponds to the values of Cahn's parameter expressed 
Fig. 3 Schematic view of the growth of single cell during DP with accompanying solute concentration profile in go-andstop period

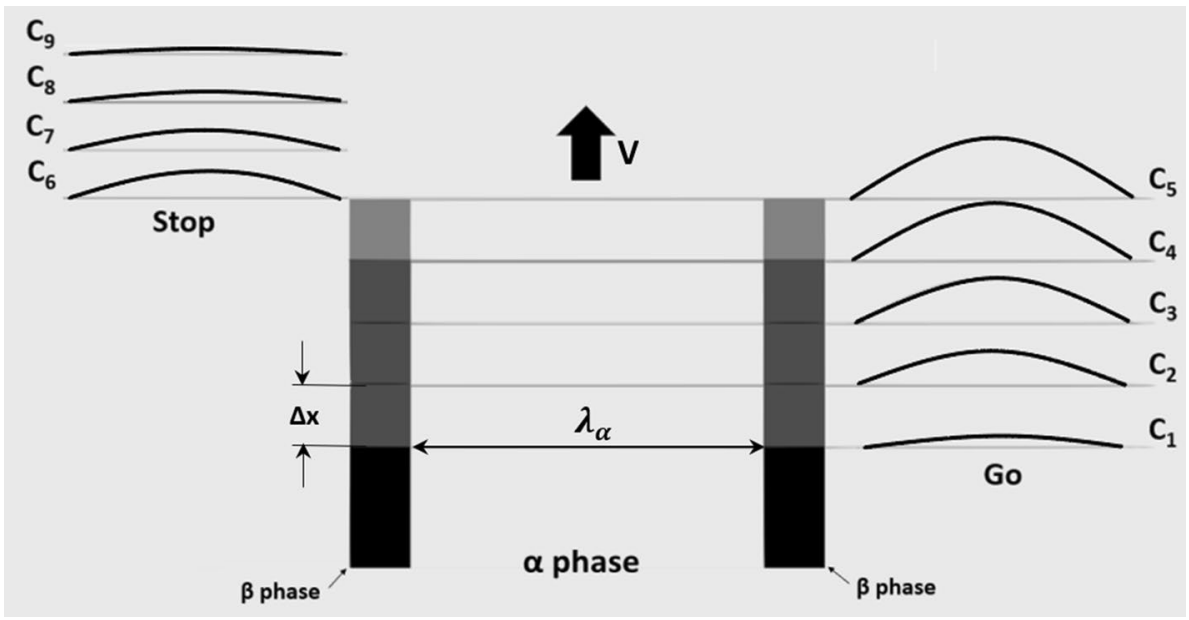

by Eq. 2 . The distance of elementary movement of the reaction front was assumed to be equal to the RF width $(\delta=5 \mathrm{~nm})$.

Table 1 contains details of the results obtained for the $\lambda_{\alpha}=100 \mathrm{~nm}$ and various values of the linear growth rate $v$. One can see that the $C$ parameter increases up to maximum preceding the RF stopping and then decreases gradually up to $C=0.89 \div 1.71$ which corresponds to hardly visible solute concentration profile. Time necessary for the go period $\left(\tau_{\mathrm{go}}\right)$ and stop period ( $\left.\tau_{\text {stop }}\right)$ is $3 \mathrm{~s}$ for the initial $v=10 \mathrm{~nm} / \mathrm{s}$ (Tables 1 and 2). The increase of linear growth rate $v$ from 25 to $30 \mathrm{~nm} / \mathrm{s}$ results in a dramatic decrease of $\tau_{\mathrm{go}}$ and $\tau_{\text {stop }}$ to tenth of a second. This is accompanied with a smaller $C$ parameter at the end of go period $\left(C_{\max }=3.89\right.$ for $v=40 \mathrm{~nm} / \mathrm{s}$ ). It is also worth to note that the motion distance increases up to $50 \mathrm{~nm}$ and the sudden decrease occurs up to $15 \mathrm{~nm}$ corresponding to above-mentioned decrease of $\tau_{\mathrm{go}}$ and $\tau_{\text {stop. }}$.

The same tendency is visible for the $v=10 \mathrm{~nm} / \mathrm{s}$ and different values of the $\alpha$ lamella thickness (Table 2). The abrupt change of $\tau_{\mathrm{go}}$ and $\tau_{\text {stop }}$ values takes place for the $\lambda_{\alpha}$ equal to $250 \mathrm{~nm}$. Also, the $C_{\max }$ is in the same range as for the assumed $\lambda_{\alpha}=100 \mathrm{~nm}$ and $v$ in the range of 10 and $40 \mathrm{~nm} / \mathrm{s}$. The only one difference is in the total distance covered by the RF which is much shorter for the $\lambda_{\alpha}=250$ and $300 \mathrm{~nm}$ and equal to 6 and $4 \mathrm{~nm}$ (Table 2).

\section{Discussion}

The presented results clearly show the nature of go-and-stop motion. The process takes place in the successive stages which can be distinguished judging from the value of $C$ parameter. However, the time necessary to accomplish the full cycle with relaxation (that means one go and one stop period) can completely be different. For lower values of linear growth rate $(v=10 \div 20 \mathrm{~nm} / \mathrm{s})$ and smaller $\alpha$ lamella thickness $(100 \div 200 \mathrm{~nm})$, the full cycle with relaxation takes 4-6 s. The faster movement of the RF $(v=30 \mathrm{~nm} / \mathrm{s})$ resulted in a dramatic decrease of the full cycle to $\tau_{\text {total }}=0.8 \mathrm{~s}$. The same behavior is observed if the $\alpha$ lamella thickness increases beyond $200 \mathrm{~nm}$ at constant $v$ equal to $10 \mathrm{~nm} / \mathrm{s}$.

The obtained results can be compared with those of Abdou et al. [1] for the Al-15 at.\% Zn alloy aged at $433 \mathrm{~K}$. They reported that the distance between two elementary goand-stop events (full cycle with relaxation) was 30-90 nm and the largest stop interval of $4 \mathrm{~s}$. This is larger than 20-50 nm obtained in the present study but corresponds well with 2-3 s shown in Tables 1 and 2. However, this is in disagreement with the maximum growth rate $110 \mathrm{~nm} / \mathrm{s}$ for time of $0.7 \mathrm{~s}$ measured by Abdou et al. [1]. On the other hand, the results shown in Table 1 indicate very short time of motion $\left(\tau_{\mathrm{g}_{0}}\right)$ equal to $0.2 \mathrm{~s}$ but for the growth rate smaller by factor 3. Such a discrepancy can be explained if we reconsider once again Fig. 1 in Ref. [1]. Then, we can easily see that not each go period is characterized by a huge jump of the growth distance. There are also intervals for which the gain of the distance is much smaller and it obviously does not correspond to the stop period. Those smaller gains take less than $5 \mathrm{~s}$. This means that we can expect two modes of the go-and-stop motion for which the growth takes either few seconds or tenths of second which confirms the results obtained in the present paper.

On the other hand, the energy-dispersive X-ray microanalysis (EDS) analysis made in the middle of $\alpha$ lamella revealed the changes of $\mathrm{Zn}$ content between 13 and 7 at.\% for two successive stages of go-and-stop motion and for the distance of about $300 \mathrm{~nm}$ for the $\mathrm{Al}-22$ at.\% $\mathrm{Zn}$ alloy aged at $423 \mathrm{~K}$ [12]. If we take the typical linear growth rates for DP process from Ref. [16] and the same alloy aged at $428 \mathrm{~K}$ migration for such distance requires ca. $\tau_{\mathrm{go}}=7-21 \mathrm{~s}$. One should remember that the linear growth rate determined by Solorzano et al. [16] was averagely taken from 10 
Table 1 Results of simulation for $\lambda_{\alpha}=100 \mathrm{~nm}$ and various values of $v$

\begin{tabular}{|c|c|c|c|c|c|c|c|}
\hline Stage & Time (s) & Parameter $C$ & $\begin{array}{l}\text { Movement } \\
\text { distance (nm) }\end{array}$ & Stage & Time (s) & Parameter $C$ & $\begin{array}{l}\text { Movement } \\
\text { distance (nm) }\end{array}$ \\
\hline \multicolumn{4}{|c|}{$v=10 \mathrm{~nm} / \mathrm{s}, \lambda_{\alpha}=100 \mathrm{~nm}$} & \multicolumn{4}{|c|}{$\nu=30 \mathrm{~nm} / \mathrm{s}, \lambda_{\alpha}=100 \mathrm{~nm}$} \\
\hline \multirow[t]{3}{*}{ Go } & 1 & 2.47 & 10 & Go & 0.1 & 1.13 & 3 \\
\hline & 2 & 6.37 & 20 & & 0.2 & 1.62 & 6 \\
\hline & 3 & 9.56 & 30 & & 0.3 & 2.44 & 9 \\
\hline \multirow[t]{3}{*}{ Stop } & 4 & 5.4 & 30 & & 0.4 & 5.25 & 12 \\
\hline & 5 & 3.77 & 30 & & 0.5 & 6.56 & 15 \\
\hline & 6 & 1.71 & 30 & Stop & 0.6 & 4.05 & 15 \\
\hline \multirow[t]{3}{*}{ Go } & 7 & 2.47 & 40 & & 0.7 & 2.4 & 15 \\
\hline & 8 & 6.37 & 50 & & 0.8 & 1.03 & 15 \\
\hline & 9 & 9.56 & 60 & Go & 0.9 & 1.13 & 18 \\
\hline \multirow[t]{3}{*}{ Stop } & 10 & 5.4 & 60 & & 1 & 1.62 & 21 \\
\hline & 11 & 3.77 & 60 & & 1.1 & 2.44 & 24 \\
\hline & 12 & 1.71 & 60 & & 1.2 & 5.25 & 27 \\
\hline \multicolumn{4}{|c|}{$v=20 \mathrm{~nm} / \mathrm{s}, \lambda_{\alpha}=100 \mathrm{~nm}$} & & 1.3 & 6.56 & 30 \\
\hline \multirow[t]{2}{*}{ Go } & 1 & 2.66 & 20 & Stop & 1.4 & 4.05 & 30 \\
\hline & 2 & 6.77 & 40 & & 1.5 & 2.4 & 30 \\
\hline \multirow[t]{2}{*}{ Stop } & 3 & 3.26 & 40 & & 1.6 & 1.03 & 30 \\
\hline & 4 & 1.37 & 40 & $v=35$ & $\mathrm{n} / \mathrm{s}, \lambda_{\alpha}=10$ & $\mathrm{~nm}$ & \\
\hline \multirow[t]{2}{*}{ Go } & 5 & 2.66 & 50 & Go & 0.1 & 1.38 & 3,5 \\
\hline & 6 & 6.77 & 60 & & 0.2 & 2.22 & 7 \\
\hline \multirow[t]{2}{*}{ Stop } & 7 & 3.26 & 60 & & 0.3 & 5.63 & 10.5 \\
\hline & 8 & 1.37 & 60 & Stop & 0.4 & 2.3 & 10.5 \\
\hline \multicolumn{4}{|c|}{$v=25 \mathrm{~nm} / \mathrm{s}, \lambda_{\alpha}=100 \mathrm{~nm}$} & & 0.5 & 0.89 & 10.5 \\
\hline \multirow[t]{2}{*}{ Go } & 1 & 2.7 & 25 & Go & 0.6 & 1.38 & 14 \\
\hline & 2 & 6.9 & 50 & & 0.7 & 2.22 & 17.5 \\
\hline \multirow[t]{2}{*}{ Stop } & 3 & 3.91 & 50 & & 0.8 & 5.63 & 20 \\
\hline & 4 & 1.84 & 50 & $v=40$ & $\mathrm{n} / \mathrm{s}, \lambda_{\alpha}=10$ & $\mathrm{~nm}$ & \\
\hline \multirow[t]{2}{*}{ Go } & 5 & 2.7 & 75 & Go & 0.1 & 1.94 & 4 \\
\hline & 6 & 6.9 & 100 & & 0.2 & 3.89 & 8 \\
\hline \multirow[t]{4}{*}{ Stop } & 7 & 3.91 & 100 & Stop & 0.3 & 1.71 & 8 \\
\hline & 8 & 1.84 & 100 & Go & 0.4 & 1.94 & 12 \\
\hline & & & & & 0.5 & 3.89 & 16 \\
\hline & & & & Stop & 0.6 & 1.71 & 16 \\
\hline
\end{tabular}

measurements of average cell width versus time. If we take in situ determined linear growth rate even at lower temperature of $400 \mathrm{~K}$ the resulting time is 2.5-5.3 s [9]. This is in a good agreement with the data presented in Table 2 for low $v$ and $\lambda_{\alpha}$.

The EDS technique was also used in a Co-13 at.\% $\mathrm{Al}$ alloy for the determination of Al-concentration profiles across the $\alpha$ lamella at the various distances from the RF [11]. Three maxima of the parameter $C$ around $5.2 \pm 5.4$ were distinguished. Then, abrupt change down to $3.4 \pm 3.7$ was observed. Such a sequence repeated three times over the distance of $350 \mathrm{~nm}$. This means that go period was extremely short approaching $\tau_{\mathrm{go}}=1.12 \mathrm{~s}$ for the linear growth rate $89 \mathrm{~nm} / \mathrm{s}$ or even $\tau_{\mathrm{go}}=0.23 \mathrm{~s}$ for $432 \mathrm{~nm} / \mathrm{s}$ [11]. Again, we have a good fit with our results and indication that this second type of movement takes tenths of second. Further, if we compare the values of $C_{\max }$ (Tables 1 and 2) we can see that in most cases these values are between 5.29 and 6.56 which is in good agreement with the results obtained for the Co-13 at.\% Al alloy. The discrepancy concerning the lowest values of $C$ preceding subsequent stage of movement can be attributed to the fact that the solute concentration profiles should be made with the step 1-4 nm which was not a case in the Co-13 at.\% Al alloy [11].

The examination of the DD reaction at $885 \mathrm{~K}$ after DP at $723 \mathrm{~K}$ in Fe-13.5 at.\% Zn alloy revealed "ghost images" of the successive positions of the receding RF with the distance between two neighboring "ghost lines" ca. 0.2-0.3 $\mu \mathrm{m}$ (see Figs. 4b, c in Ref. [7]). The average velocity of receding RF determined from measurements 50 "ghost images" width was $50 \mathrm{~nm} / \mathrm{s}$. In such a way, time for the go distance should be ca. $\tau_{\mathrm{go}}=4-6 \mathrm{~s}$. The same analysis made for the $\mathrm{Cu}-\mathrm{Cd}$ 
Table 2 Results of simulation for $v=10 \mathrm{~nm} / \mathrm{s}$ and various values of $\lambda_{\alpha}$

\begin{tabular}{|c|c|c|c|c|c|c|c|}
\hline Stage & Time (s) & Parameter $C$ & $\begin{array}{l}\text { Movement } \\
\text { distance (nm) }\end{array}$ & Stage & Time (s) & Parameter $C$ & $\begin{array}{l}\text { Movement } \\
\text { distance }(\mathrm{nm})\end{array}$ \\
\hline \multicolumn{4}{|c|}{$\nu=10 \mathrm{~nm} / \mathrm{s}, \lambda_{\alpha}=100 \mathrm{~nm}$} & \multirow[t]{4}{*}{ Stop } & 0.7 & 4.3 & 6 \\
\hline \multirow[t]{3}{*}{ Go } & 1 & 2.47 & 10 & & 0.8 & 3.11 & 6 \\
\hline & 2 & 6.37 & 20 & & 0.9 & 2.4 & 6 \\
\hline & 3 & 9.56 & 30 & & 1 & 1.67 & 6 \\
\hline \multirow[t]{3}{*}{ Stop } & 4 & 5.4 & 30 & \multirow[t]{6}{*}{ Go } & 1.1 & 2.12 & 7 \\
\hline & 5 & 3.77 & 30 & & 1.2 & 3.3 & 8 \\
\hline & 6 & 1.71 & 30 & & 1.3 & 4.67 & 9 \\
\hline \multirow[t]{3}{*}{ Go } & 7 & 2.47 & 40 & & 1.4 & 5.35 & 10 \\
\hline & 8 & 6.37 & 50 & & 1.5 & 5.67 & 11 \\
\hline & 9 & 9.56 & 60 & & 1.6 & 5.84 & 12 \\
\hline \multirow[t]{3}{*}{ Stop } & 10 & 5.4 & 60 & \multirow[t]{3}{*}{ Stop } & 1.7 & 4.3 & 12 \\
\hline & 11 & 3.77 & 60 & & 1.8 & 3.11 & 12 \\
\hline & 12 & 1.71 & 60 & & 1.9 & 2.4 & 12 \\
\hline \multicolumn{4}{|c|}{$v=10 \mathrm{~nm} / \mathrm{s}, \lambda_{\alpha}=200 \mathrm{~nm}$} & & 2 & 1.67 & 12 \\
\hline \multirow[t]{2}{*}{ Go } & 1 & 2.3 & 10 & \multicolumn{4}{|c|}{$v=10 \mathrm{~nm} / \mathrm{s}, \lambda_{\alpha}=300 \mathrm{~nm}$} \\
\hline & 2 & 5.98 & 20 & Go & 0.1 & 2.03 & 1 \\
\hline \multirow[t]{2}{*}{ Stop } & 3 & 2.91 & 20 & & 0.2 & 3.17 & 2 \\
\hline & 4 & 1.03 & 20 & & 0.3 & 4.44 & 3 \\
\hline \multirow[t]{2}{*}{ Go } & 5 & 2.3 & 30 & & 0.4 & 5.29 & 4 \\
\hline & 6 & 5.98 & 30 & Stop & 0.5 & 3.77 & 4 \\
\hline \multirow[t]{2}{*}{ Stop } & 7 & 2.91 & 30 & & 0.6 & 1.71 & 4 \\
\hline & 8 & 1.03 & 30 & Go & 0.7 & 2.03 & 5 \\
\hline \multicolumn{4}{|c|}{$v=10 \mathrm{~nm} / \mathrm{s} \lambda_{\alpha}=250 \mathrm{~nm}$} & & 0.8 & 3.17 & 6 \\
\hline \multirow[t]{6}{*}{ Go } & 0.1 & 2.12 & 1 & & 0.9 & 4.44 & 7 \\
\hline & 0.2 & 3.3 & 2 & & 1 & 5.29 & 8 \\
\hline & 0.3 & 4.67 & 3 & Stop & 1.1 & 3.77 & 8 \\
\hline & 0.4 & 5.35 & 4 & & 1.2 & 1.71 & 8 \\
\hline & 0.5 & 5.67 & 5 & & & & \\
\hline & 0.6 & 5.84 & 6 & & & & \\
\hline
\end{tabular}

alloys containing 1.82 and $2.75 \mathrm{wt} \% \mathrm{Cd}$ after prior aging at $623 \mathrm{~K}$ and dissolved at $813 \mathrm{~K}$ (Figs. 5 and 6 in Ref. [4]) provided the average distance between two successive "ghost lines" ca. 1.0 and $1.25 \mu \mathrm{m}$, respectively. This can only be compared with the average velocities 88 and $417 \mathrm{~nm} / \mathrm{s}$ determined by measurements receding distances of the RF versus time of dissolution [4]. The resulting time is between 11 and 3 s. Obviously, for all the above-discussed cases the real go time should be much shorter as the average DD velocity takes into account both go-and-stop periods. This could be even one order of magnitude as it was pointed out by Abdou et al. [1] for the DP in the Al-15 at.\% Zn alloy.

The presented examples support the idea that two different modes of go-and-stop motion of the RF operate during DP. However, which mechanism is responsible for, remains unclear. We may only speculate that a specific crystallographic or solute concentration instability can lead to the small oscillations of the RF which result in small gain of the growth distance. Such small oscillations of order of
$2 \mathrm{~nm}$ were predicted by Klinger et al. [17] who attributed the obtained results to non-steady state existing along the $\mathrm{RF}$ of discontinuous precipitates. On the other hand, better stability of the system should allow for longer time during which the RF can move.

\section{Conclusions}

The simple procedure involving Cahn's equation was presented to visualize the behavior of go-and-stop motion during DP process. The results of simulation revealed two types of such motion. The first one with longer time interval approaching several seconds is typical for rather small values of the linear growth rate of the RF and $\alpha$ phase lamella thickness. The second type which takes only tenths of second is attributed to much faster movement of the RF and relatively large thickness of the $\alpha$ phase lamella. 
Both predicted types of go-and-stop motion can experimentally be observed during growth or dissolution of discontinuous precipitates. What is the reason that particular type prevails is unknown, and this is invitation for further studies especially using high-resolution transmission electron microscope operating in in situ mode.

Acknowledgements The research was financially supported by the National Science Centre in Poland (Grant Mass transport during phase transformations at migrating boundaries of discontinuous precipitatesexperiment vs. modelling, OPUS No. 2017/25/B/ST8/02198). All the research was performed within the Accredited Testing Laboratories possessing the certificate No. AB 120 issued by the Polish Centre of Accreditation according to European standard PN-ISO/IEC 321 17025:2005 as well as the EA-2/15.

Open Access This article is licensed under a Creative Commons Attribution 4.0 International License, which permits use, sharing, adaptation, distribution and reproduction in any medium or format, as long as you give appropriate credit to the original author(s) and the source, provide a link to the Creative Commons licence, and indicate if changes were made. The images or other third party material in this article are included in the article's Creative Commons licence, unless indicated otherwise in a credit line to the material. If material is not included in the article's Creative Commons licence and your intended use is not permitted by statutory regulation or exceeds the permitted use, you will need to obtain permission directly from the copyright holder. To view a copy of this licence, visit http://creativecommons.org/licenses/by/4.0/.

\section{References}

1. Abdou S, Solorzano GI, El-Boragy M, Gust W, Predel B. In-situ study of discontinuous precipitation in Al-15 at.\% Zn. Scripta Mater. 1997;34:1431-6.

2. Bögel A, Gust W. A standardized model and a reaction principle for discontinuous precipitation. Z Metallkd. 1998;79:296-308.

3. Chongmo L, Hillert M. A metallographic study of diffusioninduced grain boundary migration in the $\mathrm{Fe}-\mathrm{Zn}$ system. Acta Metall. 1981;29:1949-60.

4. Sulonen MS. Discontinuous mode of dissolution of a $\beta$ phase precipitate into $\alpha \mathrm{Cu}-\mathrm{Cd}$ solid solutions. Acta Metall. 1960;8:669-76.
5. Tu KN, Turnbull DB. Morphology and kinetics of cellular dissolution of the Pb-Sn alloy. Metall Trans A. 1971;2:2509-15.

6. Hackney SA, Biancaniello FS. Directional invariance of grain boundary migration in the $\mathrm{Pb}$-Sn cellular transformation and the Tu-Turnbull hysteresis. Scripta Metall. 1986;20:1417-22.

7. Chuang TH, Fournelle RA, Gust W, Predel B. Drei diskontinuierliche Festkörperreaktionen in einer a-Fe-13.5 At.\% Zn-Legierung. Z Metallkd. 1989;80:318-26.

8. Pawłowski A, Zięba P. Mechanism of early stages of discontinuous dissolution in AlZn alloys. Mater Sci Eng, A. 1989;108:9-17.

9. Zięba P, Gust W. Local values of the diffusivities at the migration front of the discontinuous precipitates in Al-22 at.\% $\mathrm{Zn}$ alloy. Scripta Mater. 1998;39:13-20.

10. Zięba P, Gust W. Microanalytical study of discontinuous precipitation and dissolution in Ni-4 at.\% Sn: local and global characterization of the reactions. Acta Mater. 1999;47:2641-50.

11. Zięba P. Microanalytical study of the discontinuous precipitation in a Co-13 at.\% Al alloy. Acta Mater. 1998;46:369-77.

12. Chung YH, Shin MC, Yoon DY. In situ observation of discontinuous precipitation in an Al-40 wt\% (21.8 at.\%) Zn alloy. In: Kim NJ, editor. Proceedings of the international symposium on light materials for transportation systems (LiMAT-93). Center for Advanced Aerospace Materials, Pohang University of Science and Technology; 1993. p. 371-6.

13. Cahn JW. The kinetics of cellular segregation reactions. Acta Metall. 1959;7:18-28.

14. Tashiro K, Purdy GR. In situ observations of chemically induced grain boundary migration and discontinuous precipitation in the aluminum-zinc system. Metall Trans A. 1989;20:1593-600.

15. Zięba P. In situ study of discontinuous precipitation and dissolution in an Al-22 at\% Zn alloy. Z Metallkd. 1999;90:669-74.

16. Solorzano IG, Purdy GR, Wheatherly GC. Studies of the initiation, growth and dissolution of the discontinuous precipitation product in aluminum-zinc alloys. Acta Metall. 1984;31:1709-17.

17. Klinger L, Brechet Y, Duly D. On the influence of non-steady state velocity on interlamellae concentration profiles in discontinuous precipitation. Scripta Mater. 1997;37:1237-42.

Publisher's Note Springer Nature remains neutral with regard to jurisdictional claims in published maps and institutional affiliations 